\title{
La incorporación del hierro a la construcción en Alicante: la llegada del ferrocarril a la ciudad
}

\section{Incorporation of iron into construction in Alicante: the arrival of railway to the city}

$\underline{\text { Ma A. López Peral }}^{(*)}$, M. Louis Cereceda ${ }^{(*)}$, E. García González ${ }^{(*)}$

\section{RESUMEN}

En la segunda mitad del siglo XIX, las estaciones de ferrocarril desarrollaron nuevos sistemas constructivos, con el hierro como principal componente. Las cubiertas de los andenes exigían nuevos retos estructurales buscando la diafanidad y máxima luz entre sus apoyos. En España, Alicante fue la primera ciudad marítima conectada con una línea férrea con Madrid. Factores como la importancia del puerto, su proximidad a la capital y la favorable orografía del terreno fueron determinantes en su elección. El 25 de Mayo de 1858 quedó inaugurada la línea por la reina Isabel II. Tres décadas después, se construyó la estación de Los Andaluces que conectaba con el Sur. Actualmente ha sido restaurada y es la sede de la Casa del Mediterráneo. El presente artículo muestra los orígenes de estos dos edificios, que han podido conservar los sistemas estructurales con los que fueron diseñados hace más de 150 años.

Palabras clave: estación de ferrocarril, ferrocarriles andaluces, estructuras metálicas, Alicante, cerchas Polonceau.

\section{ABSTRACT}

In the second half of the nineteenth century, railway stations developed new building systems, with iron as the main component. The covering of large open spaces over the platforms was required as a new structural challenge. In Spain, Alicante was the first maritime city with a rail line connected with Madrid. Factors such as the importance of the port, its proximity to the capital and the favorable topography of the land were decisive in their choice. On 25 May 1858 the line was inaugurated by Queen Elizabeth II. Three decades later, Andalusian station connecting with the South was built. It has now been restored and is the seat of the House of the Mediterranean. This article shows the origins of these two buildings, which have been preserved structural systems that were designed over 150 years ago.

Keywords: railway station, Andalusian railways, metal structures, Alicante, trusses Polonceau.

(*) Universidad de Alicante (España).

Persona de contacto/Corresponding author: asun.lopez@ua.es (Ma A. López Peral)

ORCID: http://orcid.org/oooo-0oo2-4683-5279 (Ma A. López Peral); http://orcid.org/oooo-0oo1-9140-6185

(M. Louis Cereceda); http://orcid.org/oooo-0002-7384-957X (E. García González)

Cómo citar este artículo/Citation: López Peral, Ma A., Louis Cereceda, M., García González, E. (2017). La incorporación del hierro a la construcción en alicante: la llegada del ferrocarril a la ciudad. Informes de la Construcción, 69(548): e229, doi: http://dx.doi. org/10.3989/ic.16.110.

Copyright: (C) 2017 CSIC. Licencia / License: Salvo indicación contraria, todos los contenidos de la edición electrónica de Informes de la Construcción se distribuyen bajo una licencia de uso y distribución Creative Commons Attribution License (CC BY) Spain 3.o. 


\section{INTRODUCCIÓN}

Hasta mediados del siglo XIX, la construcción de los edificios estuvo condicionada por los materiales empleados, muy limitados hasta la Modernidad: piedra, ladrillo, madera o morteros de cal, formalizaban la arquitectura.

Con la segunda Revolución Industrial, aparecieron nuevos materiales que aplicados a la construcción, provocaron un cambio sustancial en la ingeniería y en la arquitectura: fundición, acero, cemento, hormigón armado, vidrio y nuevos materiales cerámicos, se integraron en las construcciones de forma paulatina, permitiendo estructuras completamente nuevas. Se inició así, un periodo de innovación en el conocimiento estructural, ligando la construcción con el diseño arquitectónico.

Como es sabido, el hierro - material milenario por excelencia- había sido utilizado en la construcción desde la antigüedad, si bien, con importantes limitaciones. En la Catedral de Santa María dei Fiore en Florencia y en la Catedral de San Pedro en Roma, Brunelleschi y Miguel Ángel, ya lo emplearon en forma de cadenas para atar las respectivas cúpulas.

Hasta la Revolución Industrial, el empleo del hierro quedó limitado como elemento de trabazón en clavos y herrajes, y para la elaboración y montaje de elementos auxiliares en la realización de las construcciones. El hierro de los hornos de carbón vegetal, se utilizó en la fabricación de las abrazaderas y pletinas de sujeción, introducidas durante el siglo XVII, para reforzar las cerchas de madera de las cubiertas. Se usaron estribos en el extremo inferior de los pendolones para independizarlo del tirante horizontal inferior.

Las piezas de hierro también se incorporaron a las fábricas de albañilería para reforzar la estructura. Se incorporaron progresivamente, grapas de hierro ocultas, llaves de atado y barras de refuerzo que permitió la construcción de grandes pórticos y columnatas (1). Otra aplicación de este primitivo hierro fue su uso con carácter decorativo. Pero con la llegada de la Revolución Industrial el empleo del hierro toma un nuevo cauce, con su producción a gran escala en alto horno empleando carbón de coke.

El empleo del hierro con fines constructivos se inició primeramente en el campo de la ingeniería. El Ironbridge sobre el río Severn, situado en Coalbrookdale, Inglaterra, es el primer puente de fundición y terminó de construirse en 1779. Su concepción se asemeja a la madera al estar la mayor parte de sus elementos comprimidos.

En el campo de la arquitectura, la columna de hierro fue el elemento protagonista durante el siglo XIX. El éxito estribó en su mayor resistencia en relación a los clásicos pilares de madera, lo que permitió la construcción de amplias salas, con el menor número de apoyos intermedios. Las luces entre las columnas de fundición se acrecentaron, permitiendo espacios diáfanos para la colocación de la maquinaria industrial. La columna de hierro se convirtió rápidamente en un elemento popular en la construcción, y empezó a utilizarse en todo tipo de edificios funcionales y, poco a poco, en las viviendas. Se adaptó a las formas más imaginativas, como las columnas de John Nash en el Royal Pavilion en Brighton, Inglaterra 1818. Por otro lado, el diseño de las columnas de la Biblioteca de Sainte Geneviève en París, de Henri Labrouste en 1851, se adaptaron a formas más clásicas (2).

\subsection{Las estaciones de ferrocarril}

Las estaciones de ferrocarril fueron el escenario perfecto para el desarrollo de los nuevos sistemas constructivos, con el hierro como principal componente. El nuevo sistema de transporte, nacido gracias a la invención de la máquina de vapor de Watt, introdujo la Estación como nuevo edificio en las ciudades. Esta tipología edificatoria, carecía de precedentes a imitar. La tecnología de la época se puso al servicio de estas construcciones, creando nuevas soluciones estructurales en las cubiertas de los andenes, que buscaban la diafanidad y máxima luz entre sus apoyos. Si el ferrocarril modificó la historia de la humanidad, al convertirse en el medio de transporte rápido que conectó territorios -favoreciendo la industria y el comercio- la estación modificó la historia de la construcción de las ciudades, al convertirse en el nuevo referente o puerta de entrada a las mismas.

La ubicación de la estación dentro de la trama urbana estaba condicionada por factores económicos (como sucedía con cualquier construcción de índole industrial) y por la propia configuración del terreno. Al igual que sucedió con la estación de Alicante, otras grandes estaciones terminales europeas de mediados del siglo XIX, como las de Estrasburgo y Metz, se instalaron en la periferia de las ciudades, bien por factores económicos, bien por imperativos militares, al imponerse su construcción fuera del perímetro amurallado de las urbes (3).

Los andenes de la Estación de Euston en Londres, fueron los primeros realizados con cerchas de cubierta completamente de hierro y su construcción la realizó el arquitecto Philip Hardwick y el ingeniero Robert Stephenson en 1835-1839. La cubierta estaba formada por dos tramos de 13 metros apoyados en pilares esbeltos intermedios de fundición. El accidente de un tren descarrilado que chocó y demolió un pilar central, causando el colapso parcial de la cubierta, puso de manifiesto la necesidad de la búsqueda de nuevas soluciones, con vanos de luz libres de apoyos intermedios. En estos inicios, destacaron la cubierta de la estación de Lime Street en Liverpool realizada por Richard Turner en 1849, de 47 metros de luz que se resolvió con cerchas curvadas y la estación de St. Pancras en Londres, de 1868, de Guillermo Henry Barlow que se resolvió con vigas en arco de celosía (4).

En España, Madrid, disponía tres estaciones al iniciar el siglo XX. Por orden de ejecución serían la Estación de Delicias, la Estación del Norte y la de Atocha. La estación de Delicias fue inaugurada en 1880. El autor del proyecto fue el ingeniero francés Emile Cachelièvre que incorporó una cubierta metálica con cerchas tipo De Dion. Dicha cubierta se proyectó de 35 metros de luz y 22 metros de altura. Henri de Dion había presentado con gran éxito, esta tipología de cubierta dos años antes, en la Exposición Universal de París de 1878.

La introducción del sistema De Dion en la estación de Delicias, fue el factor determinante para la modificación del proyecto inicial de la Estación del Norte, abandonándose el sistema Polonceau y adoptándose un sistema de cerchas inspiradas en las mejoras adoptadas en la Galería de las Máquinas de la Exposición Universal de París de 1878. La solución adoptada es atirantada, como en el sistema Polonceau, pero los pares de los cuchillos son verdaderas vigas armadas y roblonadas que se unen a los pilares de hierro que los sustentan. Estas cerchas salvan una luz de 40 metros (5). 
La tercera gran estación madrileña es la de Atocha. El edificio final es obra de Alberto de Palacio quien en 1888 ya tenía el proyecto redactado, antes por lo tanto de la Exposición Universal de París de 1889. La cubierta de Atocha, recuerda a la de la Galería de las Máquinas, en relación a su geometría de casco de nave invertido, aunque conceptualmente son muy dispares. El sistema empleado por Dutert y Contamin en la Galería de las Máquinas consistía en dos semicuchillos articulados en la clave. Alberto de Palacio, por contra, utilizó el sistema De Dion con formas curvas que es mucho más rígido. La cubierta de la estación de Atocha tiene 152 metros de largo con 10 cerchas sin tirante alguno y sin apoyos intermedios. Estos ejemplos coetáneos, ponen de manifiesto la importancia de la investigación sobre los orígenes del patrimonio ferroviario alicantino. Las primeras estructuras metálicas se realizaron a mediados del siglo XIX, coincidiendo con la construcción en Alicante de la estación de la compañía Madrid- Zaragoza y a Alicante (MZA).

\section{LA LLEGADA DEL FERROCARRIL A ALICANTE}

Alicante en el siglo XIX, presentó dos etapas antagónicas que cronológicamente coincidieron con la mitad de la centuria. En la primera mitad, la ciudad no se diferencia de la de los siglos precedentes, se encuentra amurallada, manteniendo e incluso ampliando su sistema defensivo. En la segunda mitad, coincidiendo con la inauguración de la línea ferroviaria de Madrid a Alicante por la reina Isabel II, Alicante solicitó su exención como Plaza Fuerte, iniciándose el derribo de sus murallas, abriéndose la ciudad a un nuevo periodo de regeneración urbana. Estos dos acontecimientos, marcaron un punto de inflexión en el desarrollo urbanístico de la ciudad. El primero, constituyó el inicio de la apertura de la ciudad, con la creación del Plan de Ensanche y el segundo supuso una revolución en las infraestructuras, al conectar Alicante con la capital (6).

Los orígenes de la compañía MZA se remontan a 1844. El ingeniero Pedro de Lara y Meliá obtuvo la concesión hecha por el Gobierno para construir el ferrocarril de Madrid a Alicante. Los trabajos del último tramo, Almansa-Alicante, se desarrollaron entre 1855 y 1857 (7). El 25 de Mayo de 1858 fue inaugurada la línea Madrid Alicante por la Reina Isabel II.

\section{EL PRIMER PROYECTO DE LA ESTACIÓN DE ALICANTE. MEMORIA Y PLIEGO DE CONDICIONES}

El primer proyecto de la estación de Alicante, fue redactado por el ingeniero Agustín Elcoro Berecíbar, antes de 1853. Dicho proyecto no se conserva, pero se conoce de su existencia debido a la Memoria redactada por Joaquín Gómez Ortega, ingeniero que se encargaría de juzgar el citado proyecto. Dicha Memoria sí que se conserva, se titula «Memoria sobre las estaciones del ferrocarril de Almansa a Alicante» y está fechado y firmado en Alicante, el 30 de Abril de 1853. También se conserva otro documento, que a falta del proyecto original, aporta información sobre materiales y sistemas constructivos. Este documento es el «Pliego de condiciones facultativas, que además de las generales, aprobadas por Real Orden de 18 de Marzo de 1846, han de regir en las construcción de estaciones para el ferrocarril de Alicante», fechado y firmado en Alicante el 30 de Abril de 1847, igualmente por Joaquín Gómez Ortega (8).

El texto de esta Memoria, refleja que el proyecto de Berecíbar, daba una idea general pero a su vez precisa de la zona que la vía habría de recorrer, además de la descripción de las distintas estaciones: Caudete, Villena, Sax, Elda, Novelda, San Vicente y Alicante. La Memoria, indica que el número de las estaciones, su emplazamiento y disposición debían ser acordes para que primara la economía de la explotación ${ }^{1}$.

El interés primordial era la rentabilidad de la explotación. Con este principio inicial, la construcción de las edificaciones quedó relegada a un segundo plano.

Respecto a la primitiva estación de Alicante, se concibió como una estación terminal, con el servicio de viajeros separado del de mercancías. Se propuso una cubierta en los andenes y todas las vías, sin apoyo intermedio alguno. El artículo 57 del Pliego de condiciones indica cómo ha de ser dicha cubierta: «La cubierta de la estación de Alicante será de la misma forma, construcción y materiales que las que existen en las estaciones del Grao y San Francisco de Valencia». La estructura portante de la cubierta de la estación del Grao estaba concebida con una solución mixta de madera y hierro forjado con tirantes de hierro fundido (9).

Además de la cubierta, se describe cómo ha de ser la estructura del edificio, empleándose sillería labrada en zócalos, así como en esquinas, jambas, impostas, salmeres, dinteles, arcos y cornisas. Se prohíbe absolutamente el uso de calzos y cuñas de ninguna especie en el asiento de toda sillería. En cuanto a la mampostería se elegirán piedras de formas regulares, conforme las reglas de buena construcción (artículos 19, 20, 21 y 22). El acabado final de los paramentos será el exterior con mortero de cal y arena, bruñido a paleta y los interiores con estuco de yeso blanco (artículo 46).

En este primer proyecto, no se hace alusión al empleo del hierro en ningún elemento estructural. La cubierta es tradicional y los pilares aislados se construirán de sillería en su totalidad (artículo 30).

\section{EL PROYECTO DE LA ESTACIÓN DE ALICANTE PROPUESTO POR LA COMPAÑ́ÁA MZA}

La concepción de la construcción de la estación de Alicante, cambia de raíz cuando la compañía MZA se convierte en la propietaria de la línea. Las instalaciones para la estación propuestas por Agustín Elcoro Berecíbar se quedan insuficientes, como se preveía en un principio. Se hará cargo el ingeniero francés Adolphe Jullien, venido desde París para participar activamente en la construcción de la estación definitiva de Atocha y así lo hace constar ante el Consejo de Administración de la Compañía, el 12 de Junio de 1857.

Jullien, es designado para redactar el nuevo proyecto para la estación de Alicante que se aprobará el 15 de Octubre de ese mismo año, primeramente por el Comité de París, después

\footnotetext{
Para conseguir este objetivo, la Memoria indica que «no se establecerán más edificios que los puramente precisos, sólidos pues han de tener el carácter de definitivos pero sencillos».
} 
por el Consejo de Administración de la Compañía y por último por el Gobierno.

El Consejo de Administración de la Compañía ya había aprobado cubrir por entero con una nave, las cinco vías y dos andenes disponiendo que se hiciera de hierro y cristal y sin apoyos en el centro.

Para la construcción de la estructura de hierro de la estación de Alicante, posiblemente se mantuviera la propuesta hecha por la casa «Schneider et Cie», que la compañía MZA había aceptado en Febrero de 1858, realizándola con unos cuchillos triangulares tipo Polonceau (10).

En la inauguración oficial de la estación, la armadura metálica no estaba montada. Una imagen inusual de la estación sin cubierta (Figura 1. Izquierda). La cubierta está formada por un total de 17 cuchillos que salvan una luz de 28,19 metros entre los apoyos de los muros extremos. La longitud total del espacio cubierto originario era de 85,55 metros. En la actualidad se ha realizado una extensión de la cubierta con 5 cuchillos más de la misma tipología, pero que contrastan notablemente con los originales (Figura 1. Derecha).

El edificio de viajeros de la estación se diseñó con una planta en forma de U, es decir, con un cuerpo principal de 45,57 metros de fachada y dos cuerpos laterales de 101,02 × 8,50 y $101,02 \times 14,50$ metros respectivamente, uno a cada extremo, con la pretensión de aportar todas las facilidades al usuario, (Figura 2).

\section{LA CONSOLIDACIÓN DEL FERROCARRIL EN ALICANTE. LA ESTACIÓN PROVISIONAL DE LA COMPAÑÍA DE FERROCARRILES ANDALUCES}

Tres décadas después de la llegada del ferrocarril a Alicante desde Madrid, pasaría también por la ciudad, la línea que desde Andalucía llegaría hasta Francia, por Valencia y Barcelona. La estación de Murcia fue entonces concebida como estación a término, también denominada estación de Los Andaluces o estación de Benalúa.

La inauguración de la línea de Alicante a Murcia tuvo lugar el 11 de Mayo de 1884, entrando en servicio el 18 de Junio. Se inauguró la explotación de la línea sin estar lista la estación.
La premura para la realización de la línea, demoró el interés por la construcción de la estación.

Mientras tanto, y con el fin de dar servicio a las demandas de los usuarios, se proyectó una instalación provisional de madera en 1885 , hasta la puesta en servicio del edificio definitivo. Así, con fecha 25 de Junio de 1884 se aprobaba el proyecto de edificio provisional para la estación de Alicante de la línea de Alicante a Murcia.

El edificio provisional estaba proyectado con unas dimensiones de 36,16 metros de largo por 10,50 metros de ancho. Pese a su carácter provisional, se concibió como una proporción reducida de todas las piezas indispensables para el servicio de viajeros y mercancías. El edificio destinaba parte de su superficie a un gran vestíbulo de 12,10 por 7,10 metros. Dicho vestíbulo haría también las veces de sala de espera, motivo por el cual, fue provisto de bancos para los usuarios (Figura 3).

Cuando la estación definitiva estuvo terminada, este edificio de madera se reutilizó para alojamiento del personal (11).

\section{EL PROYECTO DE M. ALEMANDY PARA LA ESTACIÓN DEFINITIVA. EL EDIFICIO DE VIAJEROS}

La línea de Alicante a Murcia con ramales a Novelda y Torrevieja fue aprobada por Real Orden de 12 de Noviembre de 1868. El emplazamiento final de la estación de Alicante, fue aprobado por Real Orden el 25 de Junio de 1884, conforme el plano de conjunto que se había presentado un año antes, el 14 de Septiembre de 1883.

Es decir, fue necesario el paso de casi veinte años desde la aprobación de la línea, para la aprobación del proyecto definitivo de la estación de Alicante.

El proyecto presentado para la estación de Alicante fue redactado y firmado por el Ingeniero M. Alemandy, en Córdoba el 19 de Febrero de 1885. El proyecto, fue aprobado con prescripciones. El Gobierno entre otros condicionantes, exigió la modificación del plano de cimentaciones, reforzando el sistema, añadiendo más pilotes a la zona del edificio de viajeros. Se realizó un plano con arreglo a lo establecido, de fecha 3 de Diciembre de 1885 . Las obras de la estación definitiva queda-
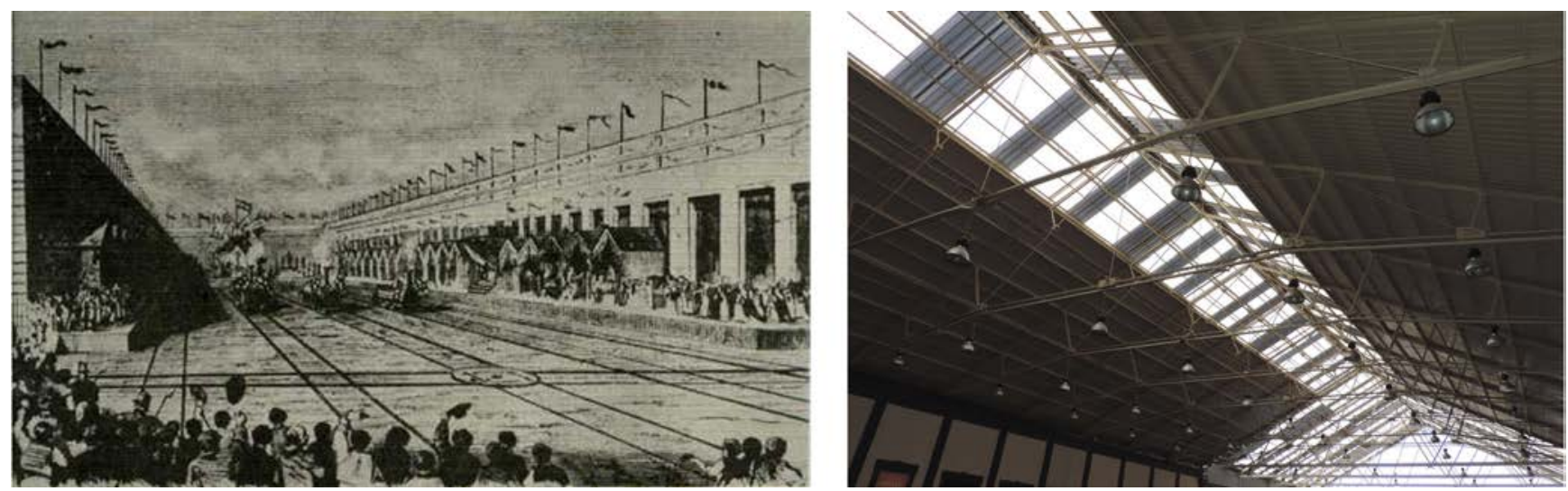

Figura 1. Izquierda. Edificio de la estación visto desde el interior. El 15 de Marzo de 1858, se inauguró en su totalidad la línea procedente de Madrid, iniciada siete años antes. Fototeca del Archivo Histórico Ferroviario. Signatura: FA- 0056- 006. Derecha. Vista actual del interior de la estación. Detalle de los cuchillos de la cubierta. 


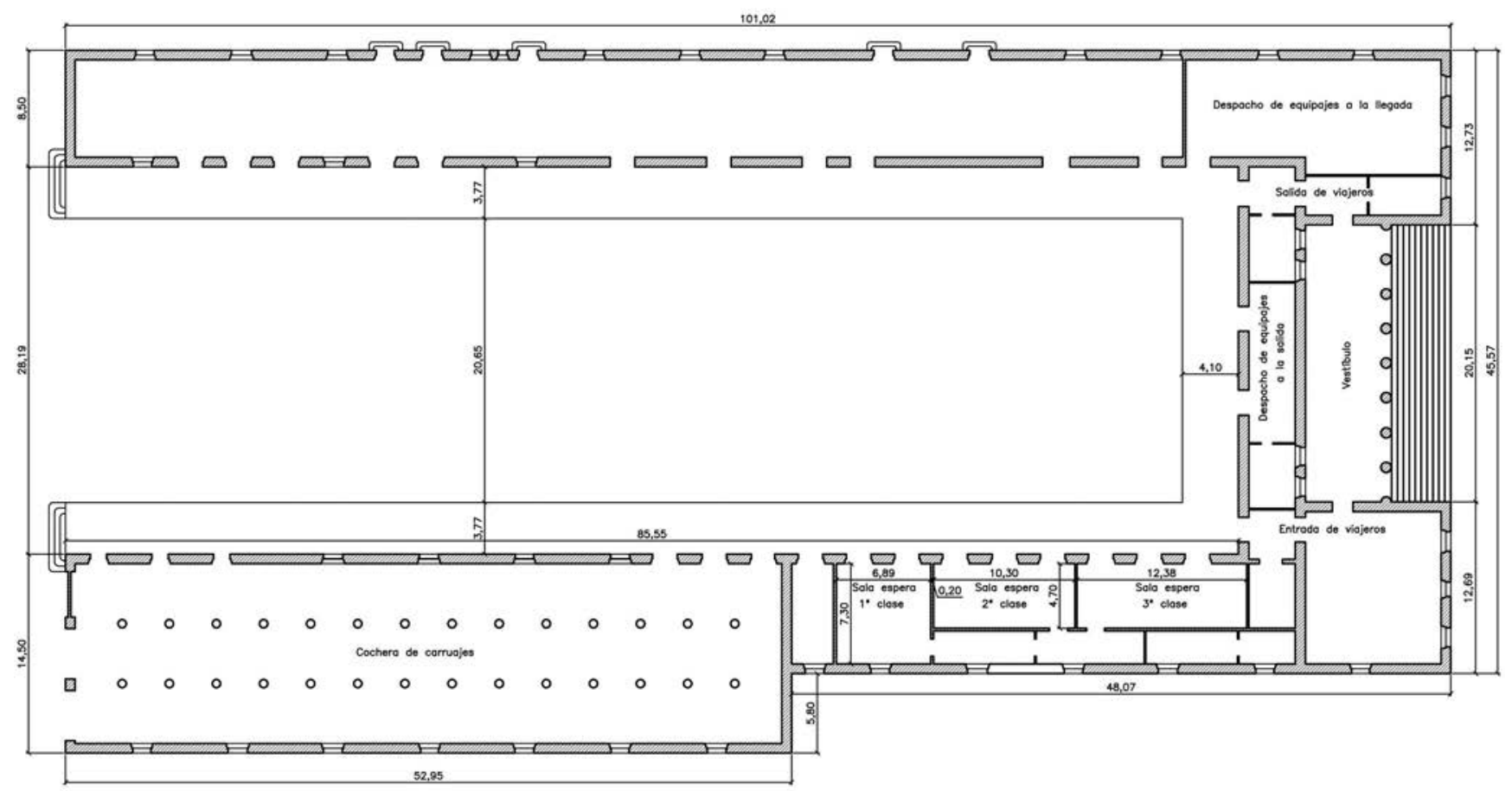

Figura 2. Planta de distribución del edificio de viajeros. Croquis basado en el plano de distribución actual del edificio de viajeros de 1906. Cotas principales.

ron finalizadas en Mayo de 1887 y el 6 de Julio se inauguraba oficialmente (12).

El plano modificado representa los pilotes originarios en tinta negra (proyecto de la compañía de fecha 19 de Febrero de 1885) y en tinta roja se indican los nuevos pilotes y su emparrillado conforme las modificaciones exigidas por el Gobierno. El corte longitudinal por $\mathrm{AB}$ y el corte transversal por $\mathrm{CD}$ representa uno de los 8 encepados con 8 pilotes cada uno que soportan las columnas de fundición que sostienen la cubierta del andén (Figura 4).

En el plano, y grafiado en tinta roja, es decir, como modificación introducida, se indica el arriostramiento en dos direcciones de todos los pilotes, además del encepado de unión de los pilotes iniciales. El arriostramiento consistía en listones de madera de escuadría cuadrada atados mediante perfilería pasante por el fuste del pilote.

La tipología del edificio de viajeros de la estación de la Compañía de Andaluces es igual al proyectado por la Compañía MZA, es decir, responde a una distribución en U. Un cuerpo principal con dos cuerpos laterales, en cuyo espacio interior, se sitúa el andén cubierto con las vías de llegada y partida (Figura 5).

El edificio se puede considerar como un exponente de la arquitectura ecléctica. La fachada del cuerpo principal presenta la sucesión de vanos y pilastras propia de la arquitectura clásica. La parte superior de los tres vanos centrales de planta baja están resueltos con arcos de medio punto. Los vanos laterales a éstos, uno a cada lado, están rematados superiormente por arcos rebajados. Sin embargo, los huecos de la planta principal son de dintel recto. La cubierta de este módulo principal del edificio es plana, delimitada por una balaustrada. En el eje de simetría del cuerpo y como emblema de la fachada se dispone el reloj sobre un escudo de la ciudad labrado en au- torrelieve. El alzado de los cuerpos laterales, tiene los huecos adintelados con arcos rebajados de medio punto. Los dos cuerpos laterales perpendiculares al primero, uno mirando al mar y otro a la carretera de Santa Pola (actual Avenida de Elche, N-332) se proyectan de 34,65 metros de largo por 8,25 metros de ancho medidos también exteriormente y de un sólo piso de 5,00 metros de altura (Figura 6. Izquierda).

El cuerpo principal del edificio de viajeros tiene unas dimensiones de 23,50 metros de largo por 11,64 metros de ancho, medido exteriormente. Está formado por dos pisos y terminado con cubierta plana. La cubierta de los cuerpos laterales es inclinada. El sistema estructural portante es con cerchas de madera sobre las que se apoyaba el enlatado de madera de pino, para recibir el acabado de la cubierta que se proyectó con teja plana. Las cerchas son sencillas, formadas por dos pares en dirección de la pendiente, un tirante horizontal, un pendolón central y dos tornapuntas (Figura 6 . Derecha).

\section{SOLUCIONES CONSTRUCTIVAS}

\subsection{Cimentación y muros}

El sistema de cimentación del edificio de viajeros se realizó mediante pilotaje de madera. En un principio se estimó la posibilidad de realizar una cimentación directa sobre el firme. Según sondeos que se realizaron, el firme era roca y se encontraba a una profundidad comprendida entre los 4,00 y los 5,50 metros. Dicha posibilidad fue desestimada, dada la propia naturaleza del terreno y su proximidad al mar. Los trabajos de agotamiento del terreno habrían supuesto un gasto desproporcionado en relación a la ventaja de cimentar directamente sobre terreno firme. La cimentación por medio de sistemas de pilotaje ofrecía resultados muy satisfactorios sin necesidad de gastos relacionados con una impermeabilización del terreno. 


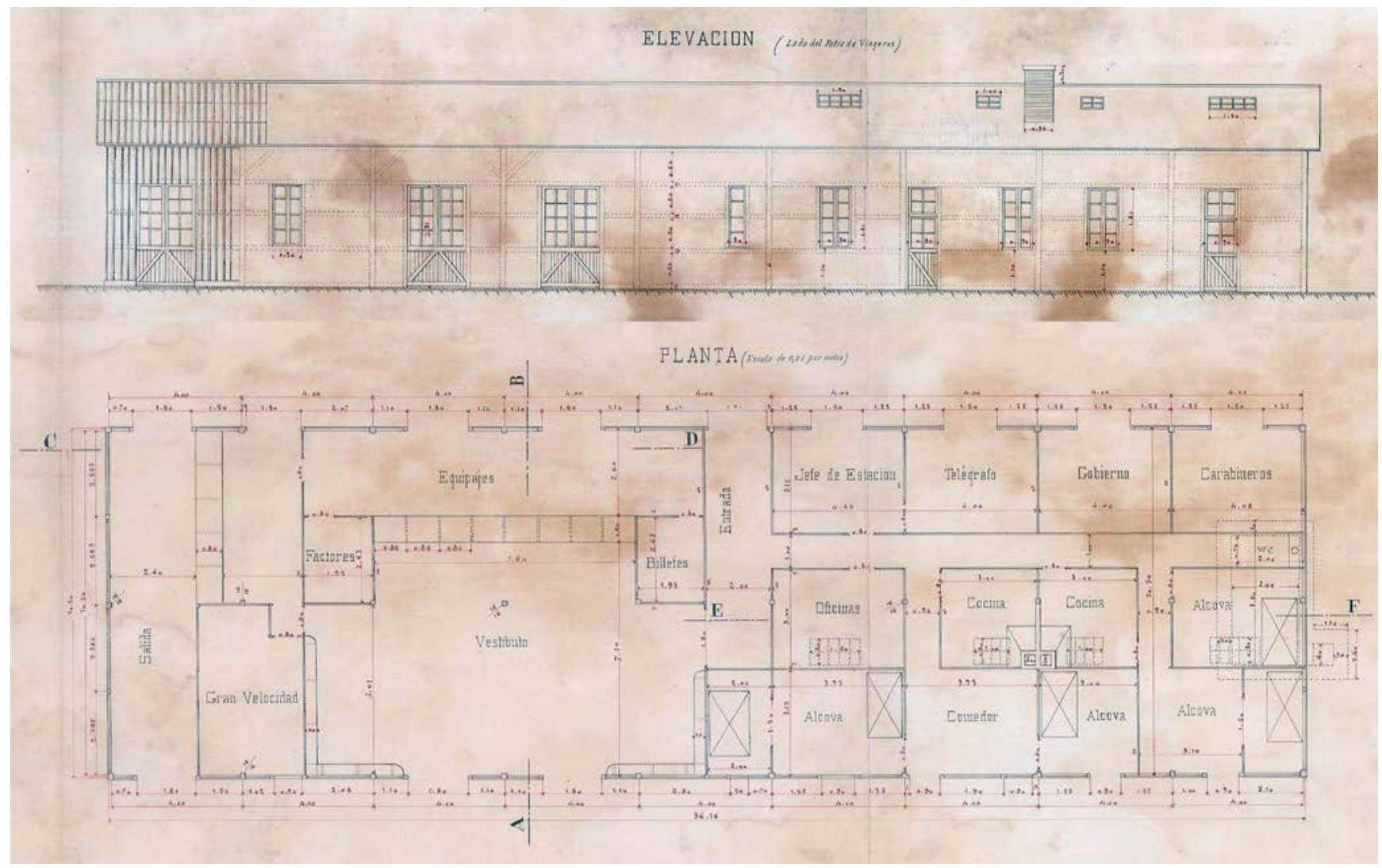

Figura 3. Plano del edificio provisional de viajeros. 20 Abril 1884. Plano de planta y alzado (Fragmento). Archivo Histórico Ferroviario Signatura: A-0004-10.
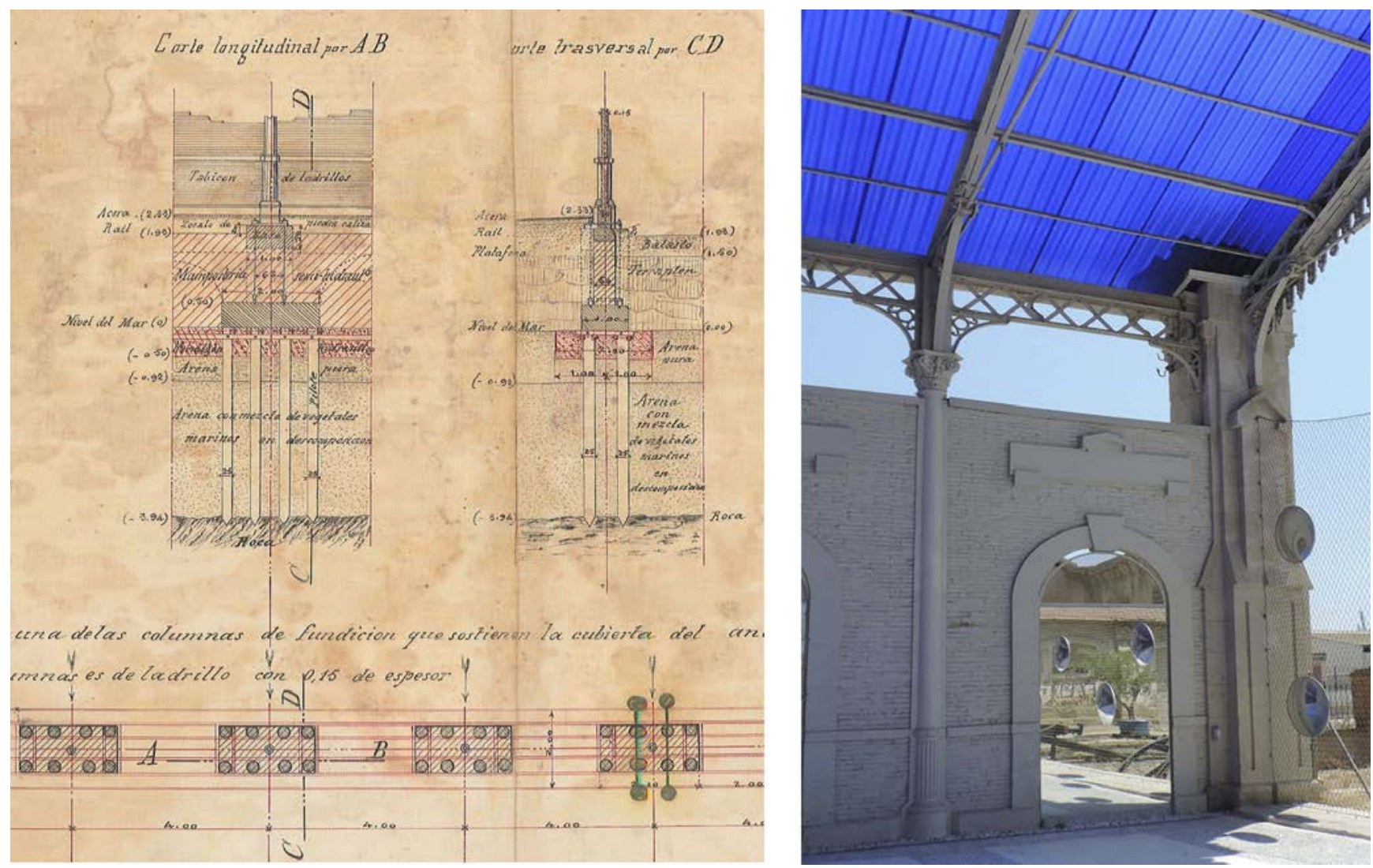

Figura 4. Izquierda. Medio Plano de fundaciones de fecha 3 de Diciembre de 1885. Detalle de la sección longitudinal y transversal de los grupos de pilotes de las columnas de fundición sobre las que apoyan las cerchas de la cubierta del andén. (Fragmento). Archivo Histórico Ferroviario. Derecha. Vista actual de una de las columnas de fundición. 


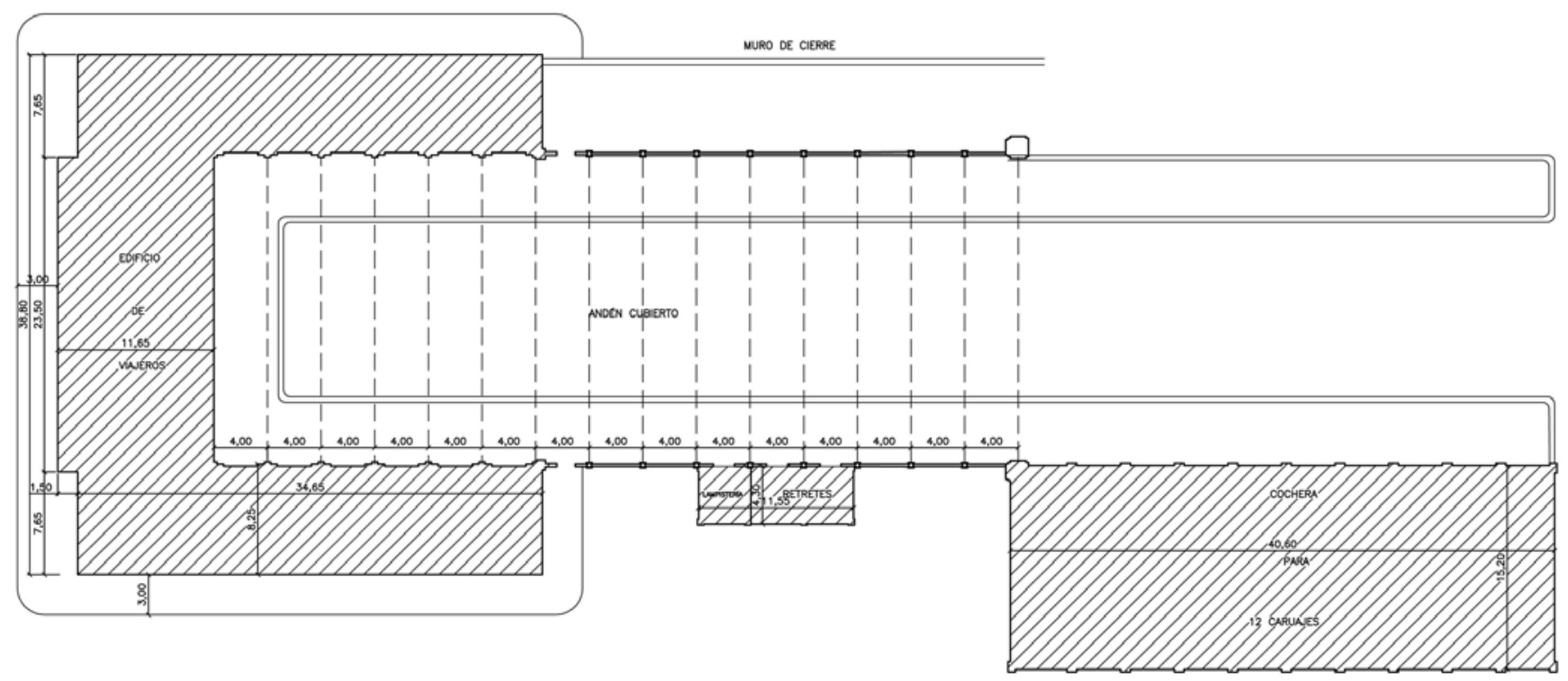

Figura 5. Plano de trabajo basado en el plano general de la estación. 19 Febrero 1885. Archivo Histórico Ferroviario Signatura: A-0007-005. Cotas generales.

Los pilotes se colocaron en grupos de 8 a 12, según la carga que debían transmitir. Los pilotes se dispusieron en dos o tres hileras dispuestas simétricamente, quedando una distancia de dos metros entre dos grupos de pilotes consecutivos. Estos pilotes fueron realizados con pino de Cuenca y de 0,24 metros de diámetro medio, por 4,00 a 5,00 metros de longitud. Se clavaron hasta la roca y las cabezas de todo el conjunto se aserraron con el fin de crear un plano horizontal, un poco más bajo que el nivel del mar. Entre los pilotes y en un perímetro de 0,50 metros alrededor de cada grupo, se colocó una capa de hormigón hidráulico quedando los pilotes sujetos entre sí.

Los muros exteriores, se realizaron de mampostería ordinaria, con piedra caliza procedente de la cantera de San Julián. Los zócalos, esquinas, cornisas, jambas y archivoltas de las puertas y ventanas y adornos, se diseñaron de sillería labrada de la cantera de San Vicente. Los enlucidos interiores se realizaron en dos capas, la primera de mortero común y la segunda de yeso blanco. Los enlucidos exteriores también se diseñaron en dos capas, la primera de mortero común y la de acabado de mortero mezclado con yeso.

\subsection{Sistema estructural adoptado en el cuerpo principal}

El forjado de la planta principal, así como el de cubierta, estaba formado por bovedillas de yeso apoyadas sobre viguetas de madera de 0,23 × 0,08 metros de escuadría, colocadas con un intereje de 40 centímetros. Estas viguetas descansaban sobre los muros principales y sobre dos vigas de hierro, distantes entre sí 4,80 metros. Estas vigas se apoyan sobre el muro de la fachada principal en la parte que corresponde al gran vestíbulo, siendo por tanto su disposición perpendicular a dicho paramento (Figura 7 ).

Cada una de estas vigas de hierro está formada por dos alas una superior y otra inferior de 200x10mm, un alma de $750 \times 10 \mathrm{~mm}$ con cuatro angulares, dos en la parte superior y dos en la inferior de $90 \times 90 \times 12 \mathrm{~mm}$, y dos angulares en la parte central de $150 \times 90 \times 15 \mathrm{~mm}$.
La solera del piso de planta baja se realizó con una ligera capa de mortero Portland, colocada sobre una capa de hormigón apoyada sobre una base de grava bien apisonada. El acabado del piso principal se proyectó con baldosa fina recibida con yeso y el solado del terrado con baldosa ordinaria sobre mortero ordinario y juntas de cemento Portland.

\subsection{Andenes cubiertos}

Entre los dos cuerpos laterales se situaron los andenes de salida y de llegada de 5,00 metros de ancho por 100,00 metros de longitud cada uno. Un conjunto de cerchas metálicas tipo Polonceau, dispuestas paralelamente entre sí, cubre los 60,00 primeros metros de dichos andenes y las tres vías que entre los mismos se establecen. Estas cerchas o cuchillos metálicos, descansan sobre los muros de los cuerpos laterales. Una vez concluidos los muros de los cuerpos laterales, el resto de los cuchillos de la estructura metálica, se apoyan sobre columnas de fundición, distantes entre sí 4,00 metros y terminadas con capiteles corintios (Figura 8. Izquierda).

El espacio comprendido entre dos columnas de fundición, se proyectó cerrado lateralmente por medio de un tabique de 0,15 metros de espesor y de 5,60 metros de altura, enlucido con mortero fino, sobre los que se situaban unas puertas con dinteles en arcos de medio punto. Dichas puertas eran ciegas, excepto la situada en el primer tramo que daba acceso a la calle y las tres últimas que daban acceso a los retretes de señoras y caballeros. Su previsión estaba motivada para la realización de futuras ampliaciones, sin que se desvirtuase la concepción original.

El espacio cubierto diseñado en la estación, tenía unas dimensiones totales de 60,00 metros de largo, 22,30 metros de ancho y 7,50 metros de alto hasta los puntos de apoyo de las cerchas. El punto más elevado estaba a una cota de 12,30 metros de altura correspondiendo con la cumbrera de los cuchillos. Para el acabado final de la estructura metálica, se colocó chapa de cinc. Sobre la cumbrera se sitúa un linternón longitudinal, en cristal.

La estructura del andén cubierto se diseñó con 15 cerchas del sistema Polonceau, distanciadas unas de otras de 4,00 me- 

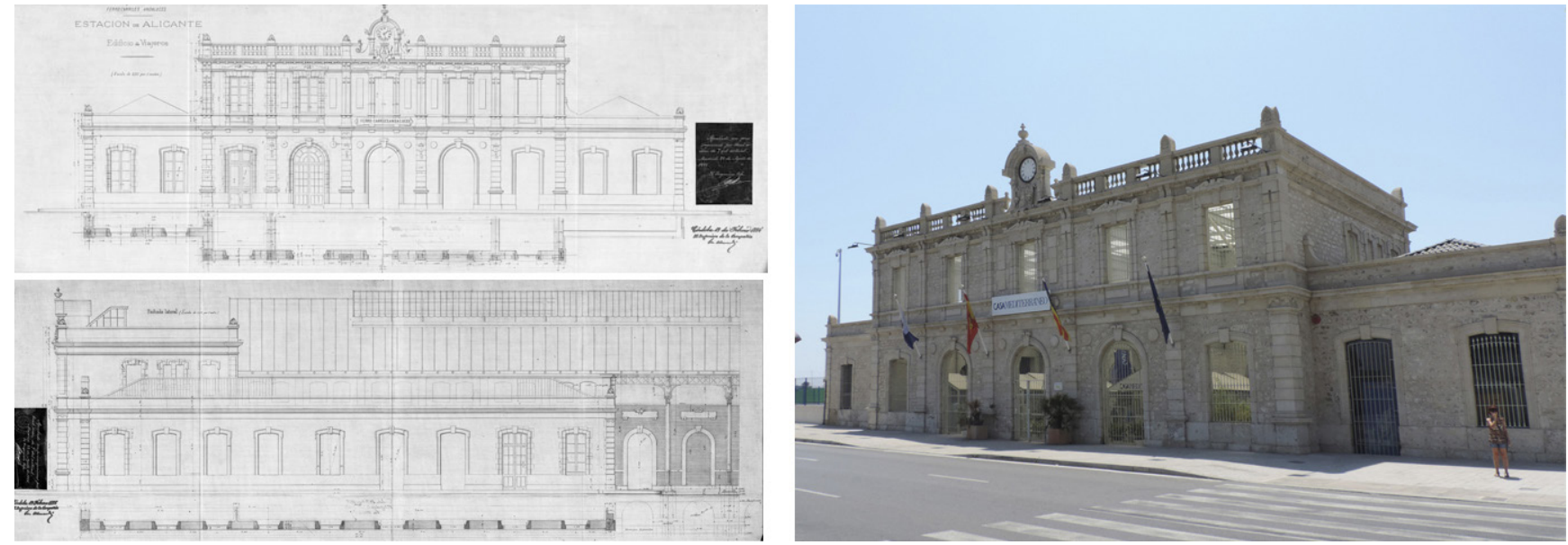

Figura 6. Izquierda. Plano de fachada principal y plano de fachada lateral. Archivo Histórico Ferroviario. Signatura: A-0007-005. Derecha. Vista actual de la estación.
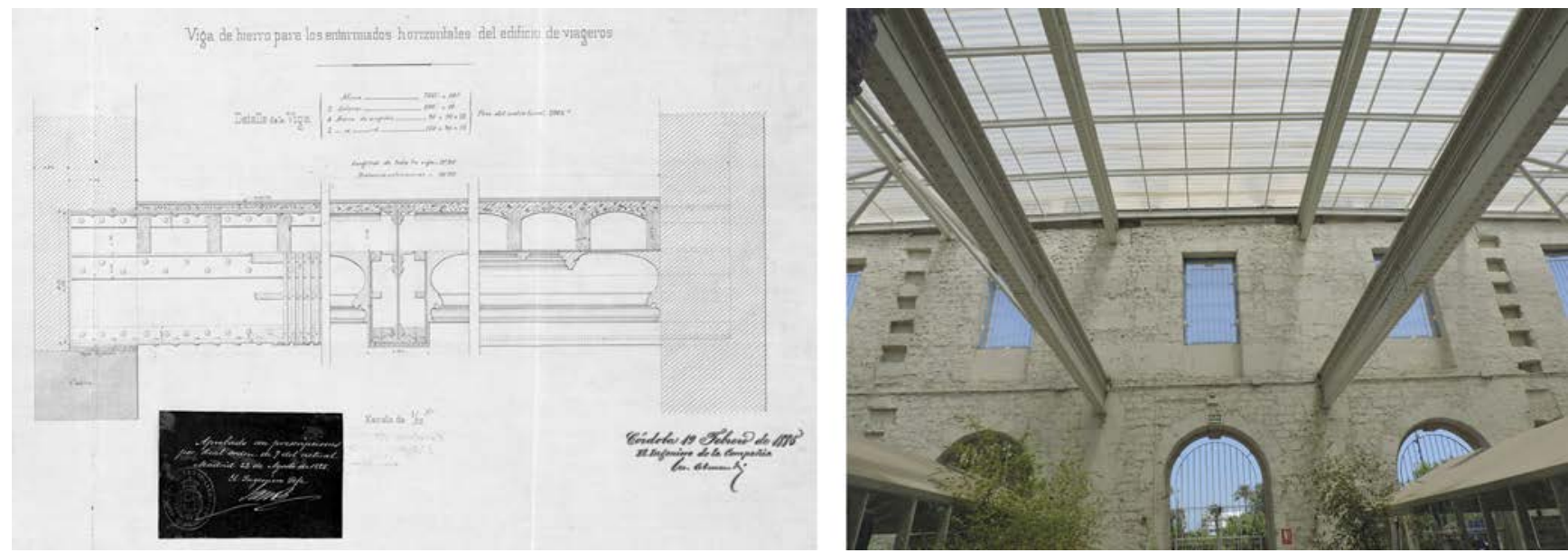

Figura 7. Izquierda. Detalle de la viga de hierro para los entramados horizontales del edificio de viajeros. Archivo Histórico Ferroviario. Signatura: A-0007-005. Derecha. Detalle de las vigas de hierro del cuerpo principal. Estado actual.

tros y unidas entre sí por vigas carreras de perfiles de hierro «I» (doble T). Sobre las cerchas descansaba un entablado de madera de 0,027 metros de espesor, destinado a recibir la chapa de cinc (13).

Los pares de las cerchas son dos grandes vigas de celosía en forma de doble $\mathrm{T}$ de $400 \times 148 \times 8 \mathrm{~mm}$, formadas en sus extremos por dos perfiles en ángulo de $70 \times 70 \times 7 \mathrm{~mm}$, reunidos dos a dos por barras de hierro de $60 \times 8 \mathrm{~mm}$ en cruces de San Andrés e inclinadas a $45^{\circ}$. En el extremo final del andén cubierto, la última cercha metálica se apoya en sendas columnas de sillería labrada configurando un pórtico monumental. La estructura metálica de cerchas de la cubierta fue construida por la empresa belga «La Louvière» (14).

\section{CONCLUSIONES}

Cuando el ferrocarril llega a la ciudad de Alicante, ésta se encuentra aún delimitada por sus murallas, aunque pronto se fueron eliminando, comenzando el ensanche de la ciudad. La idea de Puerta de entrada a la ciudad, llevaba implícita la creación de edificios monumentales, que inspiraran solidez, grandeza y confianza. Durante la segunda mitad del siglo XIX, se realizaron las dos estaciones de ferrocarril, cuyas soluciones constructivas destacan por la incorporación del hierro en sus estructuras. Actualmente la estación de MZA dista de su concepción original, no se intuye su esencia, al desaparecer de su fachada principal, su propileo de acceso y su frontón triangular superior.

Por el contrario, la estación de la Compañía de Los Andaluces, tras años de abandono, fue rehabilitada y reconvertida en la actual Sede de la Casa del Mediterráneo². El proyecto fue realizado por el Arquitecto Manuel Ocaña del Valle y los trabajos se llevaron a cabo entre 2010 y 2012 (15).

La estructura metálica de los andenes de ambas estaciones se encuentra actualmente en un correcto estado de conser-

\footnotetext{
${ }^{2}$ La casa del Mediterráneo es una Institución pública cuyo objetivo principal es fomentar la identidad común de los pueblos mediterráneos. Gestiona eventos, exposiciones, conciertos, proyecciones y todo tipo de fiestas. El 23 de Marzo de 2013 tuvo lugar la apertura pública popular y el 1 de Abril siguiente su inauguración oficial.
} 

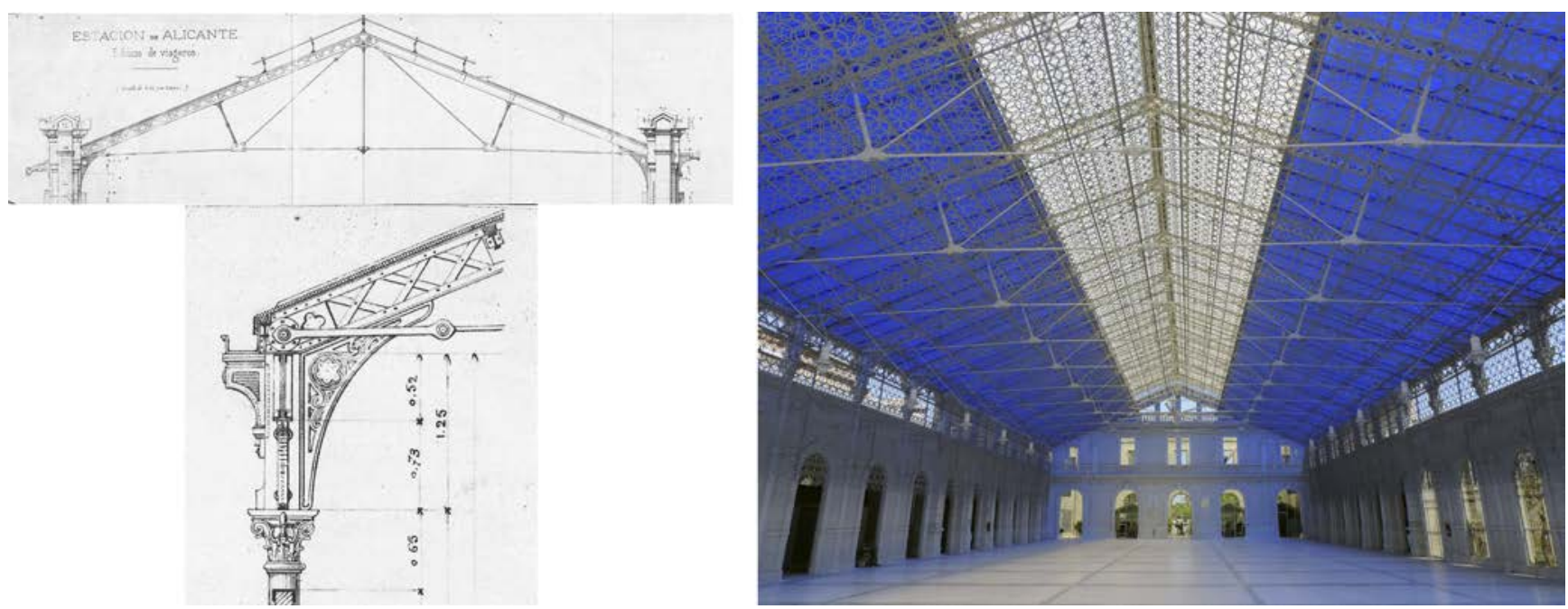

Figura 8. Izquierda. Detalle del cuchillo Polonceau del andén cubierto (Fragmento) y Detalle de los capiteles corintios de las columnas de fundición. Archivo Histórico Ferroviario. Signatura: A-0007-005. Derecha. Vista del interior de la Estación. Estado actual.

vación, siendo en el caso de la estación de Los Andaluces, su seña de identidad. Con la rehabilitación, se ha proyectado una cubierta translúcida en color azul Klein sobre los originales cuchillos Polonceau diseñados por Alemandy, con la adición de una celosía de arcos de aluminio por debajo de las vigas de celosía de los pares inclinados que forman las pendientes de la cubierta (Figura 8. Derecha). La cubierta conocida como Polonceau fue muy utilizada a mediados del siglo XIX para cubrir las naves y andenes de las estaciones de ferrocarril, como la Gare Centrale de París, abandonándose a partir de 1878 aproximadamente, al utilizarse en sustitución, el sistema De Dion.

En las naves perimetrales a este gran espacio azul central, se ha desarrollado una nueva distribución interior, creándose unos pequeños pabellones climatizados y equipados, según las nuevas demandas que la Institución necesita. Nuevos espacios para gestionar eventos, exposiciones, conciertos y demás actividades lúdicas. El resto del edificio está constantemente ventilado por aire libre debido a la ausencia total de carpinterías. Los suelos son de tierra compactada y la jardinería ha adquirido un gran protagonismo. La intervención ha pretendido destacar los elementos de valor histórico, arquitectónico y constructivo (véase el esqueleto de vigas roblonadas que formaron la estructura de los forjados del cuerpo principal del edificio, Figura 7. Derecha). El resultado se traduce en una puesta en valor del patrimonio industrial.

El patrimonio ferroviario descrito en el presente artículo se limita a la Estación. De los dos conjuntos que forman la estación, el edificio de viajeros y la nave de los andenes, el primero seguirá los preceptos de las estructuras tradicionales, con reminiscencias académicas, eclécticas e historicistas. La nave, será un campo dedicado a la experimentación, con nuevas formas y materiales. La cubierta de los andenes y las vías se desarrolló como respuesta a los imperativos técnicos impuestos por el nuevo sistema de transporte, por un lado reducir o eliminar los apoyos intermedios y por otro lado, crear un circuito de aire continuo para contrarrestar los efectos de vapor de las locomotoras.

Los edificios de viajeros de las dos estaciones alicantinas fueron diseñados con una planta en forma de $\mathrm{U}$, es decir, con un cuerpo principal y dos cuerpos laterales, uno a cada extremo, con la pretensión de aportar la mayor funcionalidad al usuario. Así, el viajero al entrar en la estación debía encontrarse lo primero con las taquillas en el vestíbulo, la expedición de equipajes, las salas de espera etc... Por otro lado, el usuario al llegar, debía poder dirigirse rápidamente a la salida, tras recoger su equipaje. El bar, restaurante, correos y demás servicios comunes se ubicaban en zonas convenientes a los dos tráficos.

La estructura de las clases sociales se reflejó desde un principio en las estaciones, en las que aparecen las salas de espera según pasajeros de primera, segunda o tercera clase. Estas salas de espera con el paso del tiempo, fueron cada vez más pequeñas, en favor del vestíbulo, de amplias dimensiones. El edificio de viajeros no sólo debía ser funcional, tanto para usuarios como para trabajadores de la estación, sino que además se le exigía un grado de monumentalidad acorde a su estatus de estación terminal.

Los otros edificios que componen el conjunto de la estación, mercancías y tracción, son también relevantes, no sólo como dependencias imprescindibles para el buen funcionamiento de la misma, sino porque adoptan también soluciones constructivas que se debieran reseñar en posteriores tratados.

\section{REFERENCIAS}

(1) Strike, J. (2004). De la construcción a los proyectos [Construction into design], p.24. Barcelona: Reverté.

(2) Giedion, S. (2009). Espacio, tiempo y arquitectura [Space, time and architecture (1 a ed 1941)], p. 274. Barcelona: Reverté.

(3) López García, M. (2005). MZA, Historia de sus estaciones, p. 41 ( $2^{\mathrm{a}}$ ed.). Madrid: Colegio de Ingenieros de Caminos, Canales y Puertos. 
(4) Frampton, K. (2010). Historia crítica de la arquitectura moderna [Modern architecture (1 ${ }^{\mathrm{a}}$ ed 1980)] (4 ${ }^{\mathrm{a}}$ rev y amp ed.). Barcelona: Gg.

(5) Navascués Palacio, P. (2007). Arquitectura e ingeniería del hierro en España (1814-1936), p.208. Madrid: Fundación Iberdrola.

(6) Martínez Ivars, C. S. (2009). El dibujo arquitectónico en la construcción de la ciudad de Alicante, p.21-25. Alicante: Instituto Alicantino de Cultura Juan Gil-Albert.

(7) AGA. Archivo General de la Administración. Caja 24/19013. Línea de Almansa-Alicante: expedientes relativos a estudios, construcción, concesión y subvenciones.

(8) AGA. Archivo General de la Administración. Caja 25/08134. Memoria sobre las estaciones del ferrocarril de Almansa a Alicante, distrito de Murcia. Caminos canales y puertos. Provincia de Alicante. Ferrocarril de Almansa. Memoria sobre sus instalaciones.

(9) Aguilar Civera, I., y Vidal Olivares, J., (coords.) (2002). 150 años de ferrocarril en la Comunidad Valenciana, 1852-2002, p.268 ( $1^{\mathrm{a}}$ ed). València: Conselleria dóbres Públiques, Urbanisme i Transports.

(10) AGA. Archivo General de la Administración. Caja 25/o8134. Informe del ingeniero jefe próximo a terminarse las obras de construcción del ferrocarril de Almansa a Alicante.

(11) AHF. Archivo Histórico Ferroviario. Expediente relativo al proyecto de estación provisional de Alicante en la línea de Alicante a Murcia, ramal de Torrevieja y Novelda. Compañía Andaluces. Servicio de Vía y Obras. Expedientes generales. Signatura: A - 0004 - 010.

(12) Ortuño Padilla, A. (coord.) (2008). El ferrocarril en Alicante: pasado, presente y futuro, p.54. Alicante, Colegio de Ingenieros de Caminos, Canales y Puertos. Delegación provincial de Alicante.

(13) AHF. Archivo Histórico Ferroviario. Proyecto de la estación definitiva de Alicante aprobado con prescripción por Real Orden de 22 de agosto de 1885. Compañía Andaluces. Servicio de Vía y Obras. Expedientes generales.

(14) Aguilar Civera, I. (1999). El Ferrocarril: Legado Cultural y Patrimonio. En Muñoz Rubio, M., Sanz Fernández, J. y Vidal Olivares, J., (Ed), Siglo y Medio del Ferrocarril en España, 1848-1998, p. 995. Madrid, Fundación de los Ferrocarriles Españoles.

(15) Coves Navarro, J. V., y González López, J. (2013). Casa del Mediterráneo y el ferrocarril Alicante-Murcia: Un recorrido histórico ( $1^{\mathrm{a}}$ ed.), p. IX. Alicante: Casa Mediterráneo. 